\title{
Surgeon is taking claims of victimisation over whistleblowing to High Court
}

In the second paragraph of the online version of this News article by Clare Dyer (BMJ 2012;345:e8247, doi:10.1136/bmj.e8247) a misunderstanding during editing led to the inclusion of the clause "The trust said that it wanted to sack him because colleagues could no longer work with him." Alder Hey Children's NHS Foundation Trust has said that it never made such a statement. Also, the online headline does not accurately reflect the article, which makes it clear that the High Court case is about a breach of contract rather than a victimisation claim. The print version is correct in both respects.

Cite this as: BMJ 2012;345:e8371

๑ BMJ Publishing Group Ltd 2012 